\title{
Normal neurophysiologic parameters of the sural nerve among adult healthy Sudanese population
}

\begin{abstract}
Background: Nerve conduction studies (NCSs) are of central importance for the assessment of peripheral nervous system disorders. They help in the diagnosis, extent distribution of neural lesion as well as the prognosis of a disease process. The aim of this study is to establish normative NCS reference data of the sural nerve in Sudanese population for our EMG electrodiagnostic center; and to survey the effects of age, gender, height, weight and temperature on conduction Parameters.

Methods: The study was conducted in Elmagzoub Neuroscience Electrodiagnostic Centre; supported by the Faculty of Medicine, National Ribat University, Khartoum, Sudan. NCSs were performed in 210 sural nerves of 105 adult healthy Sudanese subjects using standardized techniques.

Results: The Right sural nerve SNAP parameters in the whole subjects were set as (mean \pm standard deviation) for onset latency. peak latency, amplitude and conduction velocity. The values were $2.73 \pm 0.42 \mathrm{~ms}, 3.32 \pm 0.46 \mathrm{~ms}, 8.39 \pm 3.49 \mathrm{uV}$ and $52.05 \pm 8.47 \mathrm{~m} / \mathrm{s}$, respectively. The Left sural nerve SNAP parameters in the whole study group were $2.71 \pm 0.50 \mathrm{~ms}, 3.29$ $\pm 0.52 \mathrm{~ms}, 8.54 \pm 4.56 \mathrm{uV}$ and $52.66 \pm 8.95$, respectively.

Conclusion: The sural sensory nerve conduction parameters compared favorably with the existing literature. Age showed a positive correlation with latencies, and negative correlation with amplitude and velocity. Gender has conspicuous effect on all sural nerve conduction parameters. Height showed an effect on latency and conduction velocity whereas BMI revealed a negative correlation with amplitude and conduction velocity of sural nerve.
\end{abstract}

Volume II Issue I - 202I

\author{
Mohammed Salah Elmagzoub, ${ }^{1,2}$ Ahmed \\ Osman Noury ${ }^{3}$ \\ 'Department of Neuroscience, College of Applied Medical \\ Sciences, Jubail, Imam Abdulrahman Bin Faisal University, Saudi \\ Arabia \\ ${ }^{2}$ Faculty of Medicine, National Ribat University, Khartoum, Sudan \\ ${ }^{3}$ Orotta College of Medicine and Health Sciences, State of \\ Eritrea, Sudan
} Correspondence: Mohammed Salah Elmagzoub, College
of Applied Medical Sciences, Imam Abdulrahman Bin Faisal
University, Saudi Arabia, Email msmali@iau.edu.sa, msmagzoub@yahoo.com

Received: August 06, 2020 | Published: January 22, 202

\section{Introduction}

Nerve conduction studies (NCSs) are of central importance for the proper assessment of peripheral nervous system disorders. They help in the diagnosis, extent distribution of neural lesion, differentiation between demyelination and axonal degeneration as well as the prognosis and longitudinal monitoring of a disease process. ${ }^{1-4}$ Hence, it is preferable to design a nerve conductive study for each type of disease or syndrome, ${ }^{5-7}$ as recently there is increased interest in quality of normative values for each test result to be compared with patients having specific diseases..$^{8-11}$ The Sural nerve is a pure sensory nerve formed by collateral branches off the tibial and common fibular nerves. They are the medial and lateral cutaneous sural nerves, respectively. At the level of the midcalf, they join together and form a single sural nerve which continues distally and laterally alongside the Achilles tendon and then curves inferior to the lateral malleolus and passes to the lateral border of the foot, deep to the fibularis tendon sheath and reaches the lateral tuberosity of the fifth toe, where it ramifies into lateral dorsal cutaneous and lateral calcaneal branches. In the majority of people, the sural nerve has contributions from both medial and lateral sural nerves, however in rare cases, it may be formed by fibres from only the medial or the lateral sural nerve. The nerve roots commonly involved are S1 and S2. ${ }^{12-14}$

Because there is no yet normative Sudanese data against which NCS test results are to be compared, the present study, which is one of serial NCSs of upper and lower limb nerves, ${ }^{15,16}$ aims to determine the normal values of the sural nerve conduction among a group of normal healthy Sudanese people.

\section{Subject and methods}

This study has been approached through a non-interventional, clinic-based study, where 210 sural nerves of 105 healthy adult Sudanese ( $\geq 18$ years old) were recruited. The study was conducted in Elmagzoub Neuroscience Electrodiagnostic Centre; supported by the Faculty of Medicine, National Ribat University, Khartoum, Sudan. The criteria for selection of volunteers in this study was similar to that adopted in the Median and Peroneal nerves..$^{15,16} \mathrm{~A}$ verbal consent was obtained from each volunteer with maintained confidentiality. Some variables like height in centimeter; weight in $\mathrm{Kg}$.; body mass index and axillary temperature in degree centigrade were obtained prior each test. The study was performed with the subject lying comfortably at a room temperature of $25^{\circ} \mathrm{C}$. A standardized technique was used to record the sural sensory nerve action potentials (SNAPs).

\section{Equipment, stimulation and recording procedures}

As in the Median and Peroneal papers, ${ }^{15,16}$ an 8 channels EMG machine (Viaysis-select) was used, with the low frequency filter 20 $\mathrm{Hz}$; high frequency filter $2 \mathrm{kHz}$; sensitivity $20 \mu \mathrm{V} /$ division and Sweep speed of $1 \mathrm{msec} /$ division. The nerve was stimulated antidromically on the posterior surface of the lower leg $1-3 \mathrm{~cm}$ lateral to the mid-line at $14 \mathrm{~cm}$ from the recording active electrode. The active recording electrode was placed immediately behind the lateral malleolus with the inactive electrode $3-4 \mathrm{~cm}$ on the lateral surface of the foot. The ground is placed on the postero-lateral aspect of the leg between the stimulating and the recording sites. 


\section{Statistical analysis}

Analysis was done using statistical package for social sciences (SPSS) 10.0 version. Values obtained were expressed in the form of mean and standard deviation (SD). P value was taken as significant if found to be $<0.05$. The comparison between right and left sural nerve data was done.

\section{Results}

Two hundred and ten sural nerves of 105 healthy Sudanese subjects were studied. Sixty-two \% were males and 38\% were females. Their ages ranged between 22 and 62 years with an overall average of $32.22 \pm 9.98$ years. Most of them (67\%) were within the age range of 22 to 39 years. They have an average weight of $71.04 \mathrm{~kg}$, average height of $170.97 \mathrm{~cm}$ and BMI 24.225 (Table 1).

Table I Descriptive Statistics of the whole study group (I05 voluteers)

\begin{tabular}{lllll}
\hline Parameters & Minimum & Maximum & Mean & \pm SD \\
\hline Age & 22 & 62 & 36.26 & 9.978 \\
Hight & 148 & 190 & 170.87 & 8.405 \\
Body mass index & 15.1 & 34 & 24.225 & $4.628 \mathrm{I}$ \\
Body temperature & 34 & 37.8 & 36.162 & $0.785 \mathrm{I}$ \\
\hline
\end{tabular}

The Right sural nerve SNAP parameters in the whole subjects were set as (mean \pm standard deviation) for onset latency. peak latency, amplitude and conduction velocity. The values were as follow; $2.73 \pm 0.42 \mathrm{~ms}, 3.32 \pm 0.46 \mathrm{~ms}, 8.39 \pm 3.49 \mathrm{uV}$ and $52.05 \pm 8.47 \mathrm{~m} / \mathrm{s}$ respectively. The Left sural nerve SNAP parameters in the whole study group were $2.71 \pm 0.50 \mathrm{~ms}, 3.29 \pm 0.52 \mathrm{~ms}, 8.54 \pm 4.56 \mathrm{uV}$ and $52.66 \pm 8.95$, respectively. This was summarized in Tables 2 and 3 . Tables $4 \& 5$ show the parameters of the Right and Left Sural nerves in males and females, respectively whereas Table 6 shows a comparison between the values of the sural nerve obtained in the current study and some reported worldwide.

Table 2 Sensory conduction findings of the right Sural nerve. $\mathrm{N}=105$ nerves

\begin{tabular}{llll}
\hline Parameters & Minimum & Maximum & Mean \pm SD \\
\hline Onset latency $(\mathrm{msec})$ & 1.7 & 3.8 & $2.734 \pm .4153$ \\
Peak latency $(\mathrm{msec})$ & 2.1 & 4.5 & $3.324 \pm .4681$ \\
Amplitude $(\mu \mathrm{V})$ & 3 & 21 & $8.39 \pm 3.496$ \\
Distance $(\mathrm{mm})$ & 100 & 150 & $139.33 \pm 5.238$ \\
Conduction velocity $(\mathrm{m} / \mathrm{sec})$ & 37 & 82 & $52.05 \pm 8.468$ \\
\hline
\end{tabular}

Table 3 Sensory conduction findings of the left Sural nerve, $N=105$ nerves

\begin{tabular}{llll}
\hline Parameters & Minimum & Maximum & Mean \pm SD \\
\hline Onset latency $(\mathrm{msec})$ & 1.8 & 5.1 & $2.709 \pm 4964$ \\
Peak latency $(\mathrm{msec})$ & 2.1 & 5.6 & $3.289 \pm .5202$ \\
Amplitude $(\mu \mathrm{V})$ & 3 & 27 & $8.54 \pm 4.559$ \\
Distance $(\mathrm{mm})$ & 120 & 150 & $139.62 \pm 3.077$ \\
Conduction velocity $(\mathrm{m} / \mathrm{sec})$ & 27 & 78 & $52.66 \pm 8.945$ \\
\hline
\end{tabular}

Motor conduction parameters of the right peroneal nerve in female (36 nerves) The values are presented as mean $\pm S D, n=$ number, $O S L=$ Onset sensory latency, PSL = Peak sensory latency, $\mathrm{SNCV}=$ sensory nerve conduction velocity, SNAPA = sensory nerve action potential amplitude, Dis $=$ Distance between stimulating and recording electrode $* \mathrm{P}<0.05 ; * * \mathrm{P}<0.00$ I
Table 4 Comparison of right Sural nerve sensory parameters between males $\mathrm{N}=65$ and females $\mathrm{N}=40$ with reference to the whole study group $\mathrm{N}=\mathrm{I} 05$

\begin{tabular}{lllllll}
\hline Sex & & $\begin{array}{l}\text { OSL } \\
(\mathbf{m s e c})\end{array}$ & $\begin{array}{l}\text { PSL } \\
(\mathbf{m s e c})\end{array}$ & $\begin{array}{l}\text { SNAPA } \\
(\boldsymbol{\mu V})\end{array}$ & $\begin{array}{l}\text { Dis } \\
(\mathbf{m m})\end{array}$ & $\begin{array}{l}\text { SNCV } \\
(\mathbf{m} / \mathbf{s e c})\end{array}$ \\
\hline Male & Mean & 2.788 & 3.371 & 9.06 & 139.38 & 51.26 \\
N 65 & S.D & 0.4083 & 0.5012 & 3.418 & 6.092 & 8.297 \\
Female & Mean & 2.648 & 3.248 & 7.3 & 139.25 & 53.35 \\
N 40 & S.D & 0.4169 & 0.4032 & 3.383 & 3.499 & 8.687 \\
Total & Mean & 2.734 & 3.324 & 8.39 & 139.33 & 52.05 \\
N 105 & S.D & 0.4153 & 0.4681 & 3.496 & 5.238 & 8.468 \\
P-value & & 0.741 & 0.149 & $.009 *$ & 0.084 & 0.471 \\
\hline
\end{tabular}

Table 5 Effects of sex on left Sural nerve conduction parameter in both males and females

\begin{tabular}{lllllll}
\hline \multicolumn{2}{l}{ Parameter } & $\begin{array}{c}\text { OSL } \\
(\mathbf{m s e c})\end{array}$ & $\begin{array}{l}\text { PSL } \\
(\mathbf{m s e c})\end{array}$ & $\begin{array}{l}\text { SNAPA } \\
(\boldsymbol{\mu} \mathbf{V})\end{array}$ & $\begin{array}{l}\text { Dis } \\
(\mathbf{m m})\end{array}$ & $\begin{array}{l}\text { SNCV } \\
(\mathbf{m} / \mathbf{s e c})\end{array}$ \\
\hline Male & Mean & 2.797 & 3.417 & 9.72 & 139.85 & 51.26 \\
N 65 & S.D & 0.522 & 0.5153 & 5.085 & 3.304 & 8.407 \\
Female & Mean & 2.565 & 3.08 & 6.62 & 139.25 & 54.93 \\
N 40 & S.D & 0.4191 & 0.4625 & 2.628 & 2.667 & 9.426 \\
Total & Mean & 2.709 & 3.289 & 8.54 & 139.62 & 52.66 \\
N 105 & S.D & 0.4964 & 0.5202 & 4.559 & 3.077 & 8.945 \\
P-value & & $.018 *$ & $.001 *$ & $.002 *$ & $.000 * *$ & 0.294 \\
\hline
\end{tabular}

The values are presented as mean $\pm \mathrm{SD}, \mathrm{n}=$ number, $\mathrm{OSL}=$ Onset sensory latency, PSL = Peak sensory latency, SNCV = sensory nerve conduction velocity, SNAPA = sensory nerve action potential amplitude, $\mathrm{Dis}=$ Distance between stimulating and recording electrode

$* \mathrm{P}<0.05 ; * * \mathrm{P}<0.001$

Table 6 Shows a comparison between the results of the current study and those reported in other EMG laboratories. The values are presented as mean \pm SD. N: Number of sural nerve stimulated

\begin{tabular}{|c|c|c|c|c|}
\hline Studies & $\begin{array}{l}\text { Onset } \\
\text { Latency } \\
\text { (msec) }\end{array}$ & $\begin{array}{l}\text { Peak } \\
\text { Latency } \\
\text { (msec) }\end{array}$ & $\begin{array}{l}\text { Amplitude } \\
(\mu \mathrm{V})\end{array}$ & $\begin{array}{l}\text { Conduction } \\
\text { Velocity } \\
\text { (m/sec) }\end{array}$ \\
\hline $\begin{array}{l}\text { Present study } \\
N=210\end{array}$ & $2.72 \pm 0.45$ & $3.31 \pm 0.49$ & $\begin{array}{l}8.47 \pm 4.00 \\
3.6658\end{array}$ & $\begin{array}{l}52.35 \pm 8.76 \\
8.468\end{array}$ \\
\hline $\begin{array}{l}\text { Fujimaki } \\
((\text { Japan) } N=105\end{array}$ & & & $17.3 \pm 8.6$ & $52.1 \pm 5.6$ \\
\hline $\begin{array}{l}\text { WERNER T } \\
\text { (Denmark) } \\
\mathrm{N}=102\end{array}$ & & & $28 \pm 1.9$ & $53 \pm 0.34$ \\
\hline $\begin{array}{l}\text { Shaikh } \\
\text { (Nigeria) } N= \\
200\end{array}$ & 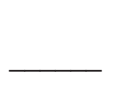 & $3.07 \pm 1.96$ & $9.6 \pm 4.8$ & $54.23 \pm 4.36$ \\
\hline $\begin{array}{l}\text { Dia Shehab } \\
\text { (Kuwait) } N=51\end{array}$ & $2.9 \pm 0.3$ & 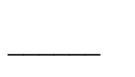 & $18.9 \pm 3.3$ & $48.7 \pm 6.0$ \\
\hline $\begin{array}{l}\text { SUE-YNG } \\
\text { ( Malaysia) } \\
N=166\end{array}$ & & & $7(2-34)^{\text {range }}$ & $4 I(38-6 I)$ \\
\hline $\begin{array}{l}\text { DIANA (USA) } \\
N=105\end{array}$ & & $3.4 \pm 0.3$ & $17.5 \pm 7.7$ & $52.2 \pm 5.3$ \\
\hline $\begin{array}{l}\text { Chi-Ren } \\
\text { (Taiwan) } \\
\mathrm{N}=|0|\end{array}$ & & & $|8.0 \pm 8|$. & $47.5 \pm 4.0$ \\
\hline
\end{tabular}


Table Continued...

\begin{tabular}{|c|c|c|c|c|}
\hline Studies & $\begin{array}{l}\text { Onset } \\
\text { Latency } \\
\text { (msec) }\end{array}$ & $\begin{array}{l}\text { Peak } \\
\text { Latency } \\
\text { (msec) }\end{array}$ & $\begin{array}{l}\text { Amplitude } \\
(\mu \mathrm{V})\end{array}$ & $\begin{array}{l}\text { Conduction } \\
\text { Velocity } \\
\text { (m/sec) }\end{array}$ \\
\hline $\begin{array}{l}\text { Zaitoon } \\
(\text { Pakistan ) N } \\
=100\end{array}$ & $2.4 \pm 0.3$ & $3.2 \pm 0.32$ & $22.5 \pm 8.8$ & $57 \pm 6.3$ \\
\hline $\begin{array}{l}\text { J McKnight } \\
\text { (north India) N } \\
=315\end{array}$ & 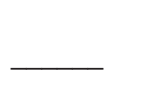 & & $18.9 \pm 8.9$ & $48.9 \pm 4.8$ \\
\hline $\begin{array}{l}\text { Thakur (Nepal) } \\
N=43\end{array}$ & $2.21 \pm 0.36$ & & $23.26 \pm 9.23$ & \\
\hline $\begin{array}{l}\text { AL-Salmi } \\
\text { (OMAN) N= } \\
\text { l } 43\end{array}$ & & $2.44 \pm 0.36$ & $12.34 \pm 5.1$ & $56.4 \pm 5.81$ \\
\hline $\begin{array}{l}\text { Kokotis } \\
\text { (Greece) } \\
N=158\end{array}$ & $2.6 \pm 0.31$ & & $19.9 \pm 6.89$ & $50.73 \pm 4.97$ \\
\hline
\end{tabular}

\section{Discussion}

This is the third article of a series of NCSs of the common upper and lower limb peripheral nerves among healthy adult Sudanese people ${ }^{(15-}$ 16). The aim of this work is to determine a normal neurophysiologic reference values of these nerves in Sudan by using standardized techniques. The study also aimed to investigate the effect of variables i.e. age, gender, height, BMI and temperature on NCS and compare them with those reported in the literature. To our knowledge no available normative data have been established in our population. As all electrodiagnostic laboratories in this country use reference values established in Western labs.

Age has been widely accepted to have an influence on nerve conduction parameters. ${ }^{10,17-23}$ The current study demonstrated a significant negative correlation between age and conduction velocity of the sural nerve. A significant positive correlation between age and onset and peak latencies was also observed. Similar association between aging and decreased amplitude and conduction velocity has been reported by McKnight et, al. in Indian population..$^{10}$ Against these findings, Buschbacher in a separate study showed that the sural onset and peak latency decreases with age. ${ }^{24}$ However, he found SNAP amplitudes and conduction velocity decline with age which inject in the same vein of our results.

Interestingly the current study showed a shorter sural SNAP onset and peak latency and a significantly faster conduction velocity in females when compared to males. This agrees with the results of Shivaji ${ }^{25}$ and Thakur ${ }^{21}$ in different regions. The amplitude of sural SNAP was found to be higher in females than males in many studies. ${ }^{10,26-28}$ which is in accordance of our results. Unlike these obtained parameters in this work Stetsod et al. showed that the onset latency of sural SNAP is longer in females. ${ }^{20}$ On the other hand, data from Saeed and Akram in a study performed in adults, reported no significant gender-related difference in the sural nerve SNAP parameters. ${ }^{29}$ The current results showed obvious influential effect of height in Sural nerve onset latency and peak latency as they increase significantly with an increase in height, while the conduction velocity decreases with the increase in height. Hence or finding are in agreement with the earlier reported inverse relationship between height and nerve conduction velocity. ${ }^{16,18,20,21,30,31}$ These results are matching the findings in the literature, ${ }^{25}$ with regards to the effects of temperature on the onset latency of Sural SNAP, which increases with high temperature, and the amplitude decreases. In the present study we could not demonstrate any significant effects of BMI on sural SNAP latencies, however an inverse relationship between amplitude and BMI was obvious. The latter is similar to the findings reported by Vineeta et al. ${ }^{32}$ The current results showed as well significant reduction in conduction velocity of sural nerve with increased BMI, which match Thakker et al findings. ${ }^{21}$

\section{Conclusion}

The sural sensory nerve conduction parameters compared favorably with the existing literature. Age showed a positive correlation with latencies, and negative correlation with amplitude and velocity. Gender has conspicuous effect on all sural nerve conduction parameters. Height showed an effect on latency and conduction velocity whereas BMI revealed a negative correlation with amplitude and conduction velocity of sural nerve.

\section{Acknowledgments}

We acknowledge the technical support of Ustz. Kholoud Abudaif, Dr. Eisa Ahmed for his help in data analysis and interpretation and Dr. Kamal Mohamed for providing statistical assistance

\section{Conflicts of interest}

The authors declare no conflicts of interest.

\section{References}

1. Benatar M, Wuu J, Peng L. Reference data for commonly used sensory and motor nerve conduction studies. Muscle Nerve. 2009;40(5):772-794.

2. Dorfman LJ, Robinson LR. AAEM minimonograph\#47: normative data in electrodiagnostic medicine. Muscle Nerve. 1997;20(1):4-14.

3. Mavor H libman. Motor nerve conduction velocity measurement. as a diagnostic tool. Neurology. 1962;12:733-744.

4. Tetro Am, Evanott BA, Hollstein SB, et al. A new provocative test for CTS. J Bone Joint Surg Br. 1998;80(3):493-498.

5. Xuan Kong, Eugene A Lesser, Frisso A Potts. Utilization of nerve conduction studies for the diagnosis of polyneuropathy in patients with diabetes: a retrospective analysis of a large patient series. J Diabetes Sci Technol. 2008;2(2):268-274.

6. Sulaiman MG. NCS and EMG in rheumatoid arthritis patients. A case control study. M.Sc. Thesis. University of Mosul. 2010.

7. Jun Kimura MD. Electrodiagnosis in disease of nerve and Muscle. Principles and practice $2^{\text {nd }}$ edn. 2001.

8. Jaffer HA, Marbut MM, AL Samarai AG. Electromyography and Nerve conductive studies in the diagnosis of lumbosacral radiculopathies. Tikrit medical Journal. 1999;5:235-239.

9. Mossa M Marbut, Raja S Najim, Muammar Abdul Mohsen. Determination of Normal Values of NC Tibial and Peroneal nerves among normal healthy subjects. Tikrit Medical Journal. 2012;18(2):1-8.

10. J McKnight, PG Nicholls, Loretta PG. Reference values for nerve function assessments among a study population in northern India - III: Sensory and motor nerve conduction. Neurology Asia. 2010;15(1):39 - 54.

11. Guyton and Hill. Textbook of medical physiology. 12th edition. NY. Saunders. 2001; p.73-74.

12. Craig A. Nerve Compression/Entrapment Sites of the Lower Limb [Internet]. Nerves and Nerve Injuries. Academic Press; 2015.

13. Richard Snell. Clinical Anatomy by Regions. $9^{\text {th }}$ edn. Lippincott Williams; 2012. p. 479.

14. Henry Gray, Anatomy of the Human Body. $6^{\text {th }}$ edition.p 604 
15. Mohammed Salah Elmagzoub, Ahmed Hassan Ahmed, Hussam M A Hameed. Normal neurophysiologic parameters of the median nerve among adult healthy Sudanese population. J Neurol Stroke. 2020;10(4):136-141.

16. Hussam Mohammed A Hameed, Mohammed Salah Elmagzoub, Ahmed Hassan Ahmed Hassan. Normative neurophysiologic parameters of the peroneal nerve among adult Sudanese population. J Neurol Stroke. 2020;10(4):147-152.

17. Yumi Fujimaki, Satoshi Kuwabara, Yasunori Sato, et al. The effects of age, gender, and body mass index on amplitude of sensory nerve action potentials: Multivariate analyses. Clinical Neurophysiology. 2009;120(9):1683-1686.

18. FJ Falco, WJ Hennessey, G Goldberg, et al. Standardized nerve conduction studies in the lower limb of the healthy elderly. Am J Phys Med Rehabil. 1994;73(3):168-174.

19. Lukman Femi Owolabi, Sunday Adebisi, Barnabas Danborno, et al. Sural Nerve Conduction in Healthy Nigerians: Reference Values and Impact of Age. Indian Journal of Clinical Anatomy and Physiology. 2015;2(4):185189

20. Parameters Chi-Ren Huang, Wen-Neng Chang, Hsueh-Wen Chang, et al. Effects of Age, Gender, Height, and Weight on Late Responses and Nerve Conduction Study. Acta Neurol Taiwan. 2009;18(4):242-249.

21. Thakur D, Paudel BH, Jha CB. Nerve Conduction study in healthy individuals a preliminary age based study. Kathmandu Univ Med J. 2010;8(31):311-316.

22. Saeed S, Akram M. Impact of anthropometric measures on surely nerve conduction in healthy subjects. J Ayub Med Coll Abbottabad. 2008;20(4):112-114.

23. Karl E Misulis, Thomas C Head. Essential of Clinical Neurophysiology. $3^{\text {rd }}$ edn. Burlington, MA. 2003. p 122-131.
24. Dia Shehaba, Mohamed AA Moussab. Normal Values of Lower Limb Nerve Conduction in Kuwait. Med Principles Pract. 1999;8:134-137.

25. Shivaji Z, Jabeen A, Awan S, et al. Developing Normative Reference Values for Nerve Conduction Studies of Commonly Tested Nerves among a Sample Pakistani Population. J Neurosci Rural Pract. 2019;10(02):178184.

26. Buschbacher RM. Sural and saphenous $14-\mathrm{cm}$ antidromic sensory nerve conduction studies. Am J Phys Med Rehabil. 2003;82(6):421-426.

27. Diana S Stetson, James W Albers, Barbara A Silverstein, et al. Effects of age, sex, and Anthropometric factors on Nerve conduction measures. Muscle \& nerve. 1992;15(10):1095-1104.

28. Robinson LR, Rubner DE, Wahl PW, et al. Influences of height and gender on normal nerve conduction studies. Arch Phys Med Rehabil. 1993;74(11):1134-1138

29. Werner T, Trojaborg MD, Agnes Moon MD, et al. Sural nerve conduction parameters in normal subjects related t to age, gender, temperature, and height: appraisal. Muscle and nerve. 1992;15:666-671.

30. Fong SY, Goh KJ, Shahrizaila N, et al. Effects of demographic and physical factors on nerve conduction study values of healthy subjects in a multi-ethnic Asian population. Muscle \& Nerve. 2016;54(2):244-248.

31. AL-Salmi K, Wali FS, Nadeem ASM, et al. Does gender have a significant effect on normal nerve conduction studies values? J Neurol Stroke. 2019;9(6):306-311.

32. Rivner $\mathrm{MH}$, Swift TR, Crout BO, et al. Toward more rational nerve conduction interpretations: the effect of height. Muscle Nerve. $1990 ; 13: 232-239$. 